\title{
Suicidality in sleep disorders: prevalence, impact, and management strategies
}

\section{Christopher W Drapeau Michael R Nadorff}

Department of Psychology, Mississippi State University, Mississippi State, MS, USA
Correspondence: Michael R Nadorff; Christopher W Drapeau

Department of Psychology, Mississippi State University, 75 BS Hood Drive, PO Box 616I, Mississippi State, MS 39762, USA

Email michael.nadorff@msstate.edu; cwdrapeau@psychology.msstate.edu
This article was published in the following Dove Press journal:

Nature and Science of Sleep

14 September 2017

Number of times this article has been viewed

Abstract: Sleep disturbances are associated with suicide-related thoughts and behaviors, and the incidence of sleep concerns and suicide has increased recently in the US. Most published research exploring the sleep-suicidality relation is focused on select sleep disorders, with few reviews offering a comprehensive overview of the sleep-suicidality literature. This narrative review broadly investigates the growing research literature on sleep disorders and suicidality, noting the prevalence of suicide ideation and nonfatal and fatal suicide attempts, the impact of several sleep disorders on suicide risk, and potential sleep-disorder management strategies for mitigating suicide risk. Aside from insomnia symptoms and nightmares, there exist opportunities to learn more about suicide risk across many sleep conditions, including whether sleep disorders are associated with suicide risk independently of other psychiatric conditions or symptoms. Generally, there is a lack of randomized controlled trials examining the modification of suicide risk via evidence-based sleep interventions for individuals with sleep disorders.

Keywords: sleep, suicide, suicidality, insomnia, nightmares, treatment

\section{Introduction}

Globally, approximately 788,000 individuals died by suicide in $2015,{ }^{1}$ and it is estimated that one suicide occurs every 40 seconds somewhere in the world. ${ }^{2}$ In the US, the crude suicide rate increased by $19 \%$ from 1999 to 2010 (10.5-12.4 per 100,000 individuals). ${ }^{3}$ During this same period, there was a $226 \%$ increase in outpatient visits related to sleep disorders among adults aged 20 years and older, with the number of sleep-medication prescriptions increasing by $293 \% .{ }^{4}$ Concerns about sleep problems in other countries have also been noted, with a study of eight countries showing that more than $20 \%$ of sampled adults reported poor sleep quality in Bangladesh, South Africa, and Vietnam. ${ }^{5}$

Sleep disturbances have been identified as a risk factor for suicide ideation, nonfatal suicide attempts, and suicide, ${ }^{6-8}$ and specific sleep-disorder symptoms (ie, insomnia and nightmares) have demonstrated unique relations to suicide-related thoughts and behaviors. ${ }^{9}$ Given the aforementioned concerns regarding the prevalence of suicide and sleep problems, including recent increases in the US suicide rate and outpatient visits for sleep-related complaints, we briefly reviewed the research literature on suiciderelated thoughts and behaviors in the varying sleep disorders to provide readers with an updated overview of the current literature. Additionally, we aimed to provide one of the first comprehensive reviews of the growing literature on suicide risk and sleep disorders, since past reviews of sleep disorders and suicidality have focused on a 
circumscribed number of sleep conditions. ${ }^{6,7,9,10}$ Finally, this review highlights the available evidence on the prevalence of suicide risk among sleep disorders, the impact of sleep disorders on suicide risk, and potential sleep-disorder management strategies for mitigating suicide risk.

For this narrative review, studies were included if 1) any measure of sleep disturbance and suicide risk was administered in the study, 2) results were published, in press, or currently being considered for publication (ie, under review) in a peer-reviewed journal, and 3) the paper or published conference abstract was written in or translated into the English language. Our search strategy for identifying relevant studies included a search of all EBSCOhost databases, including manual electronic searches of Medline (no start date to May 2017), PsycInfo (no start date to May 2017), and Google Scholar (no start date to May 2017). Examples of general search terms used to identify relevant published work included "sleep", "sleep disorder", "sleep disturbance”, "suicide", "suicidal", "suicide risk", "and suicidality". In addition to the general sleep terms utilized, the first author individually paired the names of the seven major categories of sleep disorders (eg, parasomnias) from the third edition of the International Classification of Sleep Disorders (ICSD) ${ }^{11}$ with each of the suicide-related search terms noted in the previous sentence. The first author also did this for every sleep-disorder diagnosis (eg, nightmare disorder) listed in the seven major categories to ensure that information was included for all of the sleep-disorder diagnoses listed in the most recent edition of the ICSD.

\section{Insomnia symptoms}

Along with the increased prevalence of outpatient visits noted previously, outpatient visits due to insomnia symptoms have increased 13\% from 1999 to 2010 in the US. ${ }^{4}$ Epidemiological studies estimate that up to $30 \%$ of the general population may have experienced insomnia symptoms during the past month. ${ }^{12,13}$ Prevalence estimates of adults receiving an insomnia diagnosis is substantially lower than prevalence estimates of insomnia symptoms, ${ }^{13-15}$ though they have also increased (ie, from $11.9 \%$ to $15.5 \%$ over a 10 -year period). ${ }^{16}$

\section{Prevalence of suicidality in insomnia}

There is a paucity of research estimating the prevalence of suicide-related thoughts and behaviors among individuals with insomnia. Studies examining insomnia and suiciderelated variables often do so in samples where a diagnosis of clinical insomnia is not a focal point of sample recruitment. Several studies, though, have provided some perspective on the incidence of insomnia symptoms in samples with at-risk participants (see Table 1). For participants with insomnia symptoms, the prevalence for suicide ideation was $25 \%$ $32 \%,{ }^{17,18} 7 \%-92 \%$ for nonfatal attempts, ${ }^{17,19-22}$ and $11 \%-37 \%$ among suicide decedents, with higher percentages appearing more closely to the time of death. ${ }^{23-26}$

Table I Research reporting prevalence of suicide ideation in youth and adults with insomnia symptoms and sleep disturbance among youth, adult, and older adult suicide attempters (fatal and nonfatal)

\begin{tabular}{|c|c|c|c|}
\hline & Youth & Adults & Older adults \\
\hline $\begin{array}{l}\text { Suicide } \\
\text { ideation }\end{array}$ & $\begin{array}{l}\text { Prevalence of suicide ideation was around } 25 \% \text { for } \\
\text { French adolescents reporting insomnia symptoms. }{ }^{17}\end{array}$ & $\begin{array}{l}\text { In a longitudinal study of } 405 \text { military veterans } \\
\text { meeting criteria for insomnia disorder, } 32 \% \\
\text { reported suicide ideation at baseline. }{ }^{18}\end{array}$ & - \\
\hline $\begin{array}{l}\text { Nonfatal } \\
\text { suicide } \\
\text { attempts }\end{array}$ & $\begin{array}{l}\text { About } 7 \% \text { of French adolescents with insomnia } \\
\text { symptoms reported a prior suicide attempt. }{ }^{17} \\
\text { About } 60 \% \text { of adolescents reporting intentional self- } \\
\text { harm or suicide-related behavior at age } 15-17 \text { years } \\
\text { reported sleeping problems at age } 12-14 \text { years. }{ }^{19} \\
\text { About } 81 \% \text { of adolescent suicide-attempt survivors } \\
\text { reported sleep disturbances. }^{20}\end{array}$ & $\begin{array}{l}\text { About } 46 \% \text { of adult suicide-attempt survivors } \\
\text { reported global insomnia symptoms and } 92 \% \\
\text { reported difficulties with either initial, middle, or } \\
\text { terminal insomnia. }{ }^{21} \\
\text { Around } 89 \% \text { of adult suicide-attempt survivors } \\
\text { reported sleep disturbances, which included initial } \\
(73 \%) \text {, middle }(69 \%) \text {, and terminal insomnia (58\%). }\end{array}$ & - \\
\hline Suicide & $\begin{array}{l}\text { Around } 30 \% \text { of US adolescent suicide decedents } \\
\text { experienced insomnia in the week preceding suicide } \\
\text { and } 32 \% \text { experienced symptoms around the time of } \\
\text { death. }{ }^{23} \\
\text { About } 33 \% \text { of rural Chinese youth suicide decedents } \\
\text { experienced insomnia symptoms in the week } \\
\text { preceding suicide. }{ }^{24}\end{array}$ & $\begin{array}{l}\text { Between } 28 \text { and } 37 \% \text { of Japanese suicide decedents } \\
\text { experienced initial, middle, or terminal insomnia. }{ }^{25} \\
\text { About } 60 \% \text { of US military veteran suicide decedents } \\
\text { with psychiatric symptoms reported sleep problems } \\
\text { during a VHA visit in the last year of life ( } 40 \% \\
\text { reported sleep problems at their last VHA visit). } \\
\text { About I3\% without psychiatric symptoms reported } \\
\text { sleep problems ( } 9 \% \text { at last visit). }{ }^{192}\end{array}$ & $\begin{array}{l}\text { About II\% of } \\
\text { Taiwanese suicide } \\
\text { decedents had a } \\
\text { history of insomnia } \\
\text { symptoms. }^{26}\end{array}$ \\
\hline
\end{tabular}

Notes: Initial insomnia, sleep-onset difficulty; middle insomnia, sleep-maintenance difficulty; terminal insomnia, early-morning awakening. Abbreviation: VHA, Veterans Health Administration. 


\section{Impact of insomnia on suicidality}

Difficulty sleeping and experiencing greater severity of insomnia symptoms have been associated with suicide ideation in youth, adult, and older adult samples across multiple settings and countries. . $^{17,19,27-54}$ Adolescents and adults reporting insomnia symptoms show an increased suicide risk, ${ }^{47,55-57}$ including greater odds of reporting lifetime, ${ }^{17,58-60}$ recent, ${ }^{21}$ and subsequent ${ }^{48,58,59}$ suicide attempts. Further, older adults reporting greater insomnia-symptom severity are also more likely to report a suicide-attempt history. ${ }^{61}$ Insomnia symptoms are also associated with fatal suicide attempts in retrospective, prospective, and psychological autopsy studies of youth ${ }^{23,24}$ and adults. ${ }^{24,25,62-67}$ Research among older adults has shown similar findings regarding fatal suicide attempts, ${ }^{26}$ with longitudinal research showing that poor subjective sleep increased the odds of a fatal suicide attempt 1.2 -fold $^{68}$ and nonrestorative sleep increased risk 2.2-fold. ${ }^{69}$

The odds of suicide were fivefold greater in a sample of adolescents experiencing insomnia symptoms within the week preceding suicide, with suicide decedents more likely than controls to experience a worsening of sleep disturbance in the final week preceding suicide. ${ }^{23}$ Additionally, among a sample of veteran suicide decedents, those decedents with documented sleep disturbance (ie, insomnia or hypersomnia) died significantly sooner than decedents without documented sleep disturbances. ${ }^{64}$ Longer time frames to suicide have also been observed, as a dated 10-year prospective study of 954 psychiatric inpatients with a major mood disorder showed that global insomnia (presence of onset, maintenance, and terminal insomnia) was one of six variables associated with a fatal suicide attempt within a 1-year time frame. ${ }^{63}$ Taken together, these results suggest that insomnia may function as a distal or proximal risk factor for suicide, with a role in both imminent and long-term suicide risk.

\section{Insomnia and suicidality inconsistencies}

Diverging from the studies reviewed thus far, Pompili et $\mathrm{al}^{70}$ found no significant differences in suicide ideation or suicide-attempt history between those reporting and denying insomnia symptoms in a sample of 843 patients admitted to an emergency department in Rome. However, they did find that those reporting insomnia symptoms more frequently used a violent suicide-attempt method. Furthermore, a few studies have shown that the presence of a psychiatric illness ${ }^{24}$ or depressive symptoms $\mathrm{s}^{36,41,52,71}$ have an indirect effect on the relation between insomnia symptoms and suicide-related variables. However, across numerous studies, associations between insomnia symptoms and suicide-related variables have been independent of depressive symptoms and/or other potential confounders (ie, age, sex, fatigue, chronic health problems, anhedonia, hopelessness, anxiety symptoms, substance use, cognitive ability, or the presence of any psychiatric illness). ${ }^{19,23,25,30,31,33,34,40,42,46,48,51,57,61,64,66,68,69,72-74}$

Additional inconsistencies include the risk conferred by specific insomnia symptoms (see Table 2). Research does not show a clear pattern regarding whether onset, maintenance, or terminal insomnia independently heighten suicide risk, with several studies showing that concurrently reporting two of these three insomnia symptoms may confer greater risk for suicide ideation ${ }^{40,42,46,57}$ and attempts, ${ }^{30,31,75,76}$ intent to attempt suicide, ${ }^{72}$ and death by suicide. ${ }^{66}$ This suggests that greater risk may result from the presence of multiple sleep disturbances..$^{54,66,73}$

In an attempt to understand the insomnia-suicide relation better and perhaps account for the aforementioned

Table 2 Inconsistencies in insomnia symptoms and suicidality research

Initial insomnia Initial insomnia has been associated with current ${ }^{51}$ and past I2-month suicide ideation, suicide-attempt planning, and nonfatal suicide attempts, ${ }^{73}$ and has been independently associated with youth suicide, ${ }^{23,24}$ but was shown to be protective against attempting suicide at age 15-20 years. ${ }^{193}$

Middle insomnia Middle insomnia has been independently associated with suicide in youth ${ }^{24}$ and adult ${ }^{65}$ samples, and has been associated with an increased frequency of lifetime suicide attempts, ${ }^{140}$ with adolescents reporting middle insomnia showing a four- ${ }^{179}$ to sixfold ${ }^{193}$ greater likelihood of reporting a past suicide attempt than those without middle insomnia. The relation between middle insomnia and suicide ideation, however, has not been consistent, though it should be noted that the majority of studies have shown an association between these two variables and the few inconsistencies do not appear to depend on whether researchers adjusted for psychiatric illness or other covariates, given that this was done across the majority of studies. ${ }^{30,31,40,42,46,57,140}$

Terminal insomnia Regarding terminal insomnia, a few studies have shown that terminal insomnia is associated with suicide ideation (independently of mood, anxiety, and substance-use disorders), ${ }^{140}$ greater intent to attempt suicide, ${ }^{128}$ and recent suicide attempts, ${ }^{73,76}$ but not lifetime suicide attempts. ${ }^{140} \mathrm{~A}$ study of Chinese adolescents showed that terminal insomnia did not predict significantly greater odds of suicide ideation when adjusting for age, sex, father's occupation, and depressive symptoms. ${ }^{117}$

Notes: Initial insomnia, sleep-onset difficulty; middle insomnia, sleep-maintenance difficulty; terminal insomnia, early-morning awakening. 
inconsistencies, researchers have explored several potential mechanisms ${ }^{77}$ (see Table 3 for a summary). It is important to note that much of the mediation research thus far has been atemporal, due to the cross-sectional or baseline-follow-up research methods employed, limiting conclusions regarding temporality. ${ }^{78}$ More than two time points may be necessary, in order to infer temporal ordering of mediation. ${ }^{78}$

\section{Management of suicidality and insomnia}

Researchers have continuously called for greater empirical focus on the investigation of insomnia-treatment effects on mitigating suicide risk. ${ }^{33,64,79-83}$ Although studies examining the efficacy of insomnia treatments on reducing suicide risk have been conducted, ${ }^{84}$ there is a significant need for more research (ie, randomized controlled trials). Cognitive

Table 3 Summary of mechanisms examined in the insomnia-suicidality relation

\begin{tabular}{ll}
\hline Proposed mediator & Summary of research \\
\hline Hopelessness & Hopelessness had an indirect effect on the insomnia-suicide ideation relation in a cross-sectional sample of US adults, \\
& independently of depressive symptoms. ${ }^{194}$ However, other studies have shown that the insomnia symptom-suicide ideation \\
& relation remains when adjusting for depressive symptoms and feelings of hopelessness. ${ }^{48}$ Additionally, a case study of a \\
& 64-year-old male admitted to a psychiatric hospital after a suicide attempt noted that the patient's feelings of hopelessness \\
& were secondary to insomnia distress and resolved, along with suicide ideation, following sleep improvements. ${ }^{195}$ Finally, in \\
& a study of adults with depression, hopelessness did not relate to insomnia symptoms or dysfunctional beliefs and attitudes \\
& about sleep, ${ }^{43}$ which is notable, given that it has been argued that some of the items on the DBAS measure reflect feelings \\
& of hopelessness. ${ }^{196}$
\end{tabular}

Depression Allan et $\mathrm{al}^{71}$ suggested that the structure of depression (ie, cognitive/affective symptoms vs somatic) may explain the structure discrepant depression-mediation results across studies. In their sample of 405 current and former US military personnel, cognitive/affective symptoms of depression had an indirect effect on the relation between insomnia symptoms and baseline and I2-month follow-up suicide-ideation levels.

Insomnia duration Research has shown that the duration of insomnia symptoms is associated with suicide risk independently of current symptoms of insomnia, depression, anxiety, or PTSD. ${ }^{177}$ Furthermore, a random-digit-dial study of US adults showed that insomnia complaints were more strongly associated with suicide ideation than ratings of poor sleep, ${ }^{197}$ and other studies have shown higher levels of suicide ideation among participants whose sleep concerns did not improve over the course of the treatment (independently of baseline sleep concerns, depressive symptoms, and suicide ideation) ${ }^{198}$ and that sleep dissatisfaction can explain a significant portion of the relation between insomnia and the wish to die. ${ }^{129}$

DBAS In addition to nightmares, it has been proposed by McCall et al that DBAS may explain part of the relation between insomnia symptoms and suicide ideation due to the indirect effect of DBAS approaching significance in their cross-sectional sample of adults with depression. ${ }^{43}$

Nightmares Nightmares have received increased attention over the past decade with regard to their potential role as a mediator of the insomnia-suicide relation. Research has shown that nightmares are associated with insomnia symptoms, ${ }^{43,199}$ independently predictive of suicide ideation in cross-sectional samples, ${ }^{38,89,165}$ and that the relation between insomnia symptoms and suicide ideation becomes nonsignificant when including nightmares ${ }^{43}$ and holding symptoms of anxiety, depression, and PTSD constant. ${ }^{38}$ Furthermore, coexisting insomnia symptoms and nightmares have been shown to increase the risk for a future suicide attempt in an adult sample of psychiatric outpatients, ${ }^{58}$ potentially supporting the supposition that nightmares may be one reason for middle insomnia. ${ }^{60}$

Hyperarousal Insomnia and PTSD-related nightmares have both been proposed as conditions of hyperarousal, ${ }^{196}$ and hyperarousal during sleep has been proposed as a neurobiological correlate of suicide ideation in adults with major depressive disorder. ${ }^{200}$ Recent studies have examined the role of hyperarousal in suicide risk, ${ }^{201}$ and a study of US military personnel showed a stronger relation between insomnia symptoms and suicide ideation among those with heightened levels of agitation. ${ }^{35} \mathrm{~A}$ dated study of suicide-attempt survivors, however, showed that $89 \%$ of attempt survivors denied experiencing agitation in the week prior to their suicide attempt. ${ }^{21}$

Thwarted Recent research has examined the indirect effect of thwarted belongingness, a variable included in the suicidal desire belongingness component of the IPTS, ${ }^{202}$ on the relation between insomnia symptoms, suicide ideation, and suicide risk, showing that the variable accounts for a significant portion of the relation between insomnia and suicide ideation across multiple samples. ${ }^{39,47,56}$ However, it should be noted that the indirect effect of thwarted belongingness on the relation between insomnia and suicide risk was not significant when adjusting for depressive symptoms, ${ }^{47}$ and prior research has shown that the IPTS or thwarted belongingness alone fail to mediate the relation between insomnia symptoms and past suicide attempts cross-sectionally. ${ }^{74}$ Furthermore, the results from Hom et al ${ }^{47}$ specifically showed that the indirect effect of thwarted belongingness on the relation between insomnia and suicide ideation was more meaningful for those with lower levels of perceived burdensomeness. This finding potentially conflicts with the IPTS as originally proposed, ${ }^{202}$ and suggests that the IPTS may not be able to explain how insomnia symptoms lead to increased suicide risk across all samples, which is consistent with previous research. ${ }^{74}$

Abbreviations: DBAS, dysfunctional beliefs and attitudes about sleep; PTSD, posttraumatic stress disorder; IPTS, interpersonal-psychological theory of suicide. 
behavioral therapy for insomnia (CBT-I) is one insomnia treatment that appears promising for mitigating suicide risk in insomnia patients. CBT-I is currently recommended as the initial treatment for chronic insomnia in adults, ${ }^{85}$ and is associated with significant reductions in suicide-related thoughts from pre- to posttreatment. ${ }^{18,84,86}$ Researchers have continuously called for greater empirical focus on investigating the effects of insomnia treatment on mitigating suicide risk. $^{33,64,79-83}$ We also argue that such research is needed, especially since there has not been enough research to establish adequate efficacy and because prescription sleep medications (eg, sedative-hypnotics) have been associated with suicide ideation $^{34}$ and suicide, ${ }^{57,87}$ and were a stronger predictor of past-year suicide ideation and nonfatal suicide attempts than insomnia symptoms in a general US population sample. ${ }^{88}$

\section{Sleep-related breathing disorders}

The number of outpatient visits resulting in a diagnosis of sleep apnea increased $442 \%$ from 1999 to $2010,{ }^{4}$ but the prevalence of suicide-related thoughts and behaviors among sleep-apnea patients is currently unknown. Studies have shown mixed findings regarding the relation between sleep apnea and suicide risk. Sleep-related breathing symptoms were not related to suicide ideation in an adult outpatient sample ${ }^{89}$ but have been associated with suicide ideation and suicide-attempt planning in a general population sample of adults $^{90}$ and greater depression severity and suicide risk in a sample of female sexual assault survivors (compared to those without sleep-related breathing symptoms). ${ }^{91}$ In the latter study, the greatest suicide risk was shown for those participants presenting with concurrent sleep-related breathing symptoms and a sleep-movement disorder. It is unknown if a coexisting psychiatric illness or sleep disorder would explain the discrepant findings between these two studies. For instance, research has shown that $39 \%-61 \%$ of obstructive sleep-apnea patients also have insomnia symptoms. ${ }^{92-94}$ It remains to be seen if sleep-related breathing symptoms are associated with suicide-related thoughts and behaviors independently of other sleep or psychiatric disorders.

Results from a case report and a study of adults assessed for obstructive sleep apnea suggest that treatment of sleeprelated breathing via nasal continuous positive airway pressure may resolve suicide-related thoughts. The case study ${ }^{95}$ focused on a 74-year-old male presenting with severe depression, excessive daytime sleepiness, and suicide ideation with a suicide-attempt plan, and noted that treatment of sleep-apnea symptoms appeared to lead to the resolution of depressive symptoms (a result supported by prior research) $)^{96}$ and suicide risk. In the study of adults assessed for obstructive sleep apnea, Edwards et $\mathrm{al}^{97}$ showed that among the subset of the sample that reported suicide ideation at baseline, none endorsed suicide ideation after 3 months of continuous positive airway-pressure adherence.

More research is needed, especially studies using objective sleep measures, in order to ascertain suicide risk among patients with central or obstructive sleep apnea. Additionally, little is known about the contribution of snoring to suicide risk. One study showed higher suicide risk for South Korean adolescents who reported snoring compared to those who denied snoring, ${ }^{55}$ though snoring did not appear independently to contribute to suicide risk when adjusting for other sleep-related variables. Lastly, it is unknown if other sleeprelated breathing disorders, such as sleep-related hypoventilation disorders or catathrenia, confer an increased suicide risk.

\section{Central disorders of hypersomnolence Narcolepsy}

When compared to the general population, patients with narcolepsy have an increased mortality risk across all agegroups. ${ }^{98}$ Although few studies have examined the prevalence of suicide risk, results from the Burden of Narcolepsy Disease study showed that patients with a narcolepsy diagnosis were at increased risk of suicide-related behavior compared to matched controls, including increased odds of having a depressive or anxiety disorder. ${ }^{99}$ Also, Ohayon ${ }^{98}$ discussed results from an unpublished longitudinal study of narcolepsy patients ${ }^{100}$ showing a sevenfold-greater risk for suicide among those with narcolepsy. More research is needed in order to understand better whether aspects of narcolepsy confer greater suicide risk or if the risk can be explained by a concurrent psychiatric illness (eg, depression). Furthermore, it is unknown if narcolepsy treatment can allay suicide risk.

\section{Idiopathic and other hypersomnias}

Hypersomnia symptoms have been associated with suicide ideation $^{101}$ and nonfatal suicide attempts ${ }^{102}$ in adolescents. Hypersomnia symptoms have also been associated with increased suicide risk ${ }^{103}$ and higher odds of past-year and lifetime nonfatal suicide attempts in a sample of depressed adults. ${ }^{104}$ Hypersomnia has also been associated with pastyear suicide ideation and suicide-attempt planning when experienced concomitantly with insomnia symptoms. ${ }^{104}$ Goldstein et $\mathrm{al}^{23}$ found a higher prevalence of hypersomnia in adolescent suicide decedents compared to community controls. Based on information from decedent informants, 
$15 \%$ of adolescent suicide decedents experienced hypersomnia in the week preceding suicide and $16 \%$ experienced hypersomnia around the time of suicide. Additionally, it was more likely for the suicide decedents' hypersomnia symptoms to worsen in the week preceding suicide (compared to controls). ${ }^{23}$ However, a psychological autopsy study of adult suicide decedents showed that the concurrent presence of hypersomnia with other depressive symptoms (ie, fatigue, impaired concentration/indecisiveness, and weight/appetite gain) was associated with decreased risk for suicide. ${ }^{62}$ More research is needed to determine if hypersomnia increases suicide risk independently of concurrent psychiatric illness symptoms, and if so, whether management of hypersomnia can mitigate suicide risk.

\section{Kleine-Levin syndrome}

Very few studies have investigated the prevalence of suicide risk in patients with Kleine-Levin syndrome (KLS). One study of 108 KLS patients showed that $3.7 \%$ of the sample endorsed thoughts of attempting suicide, ${ }^{105}$ but no other studies to our knowledge have examined suicide-specific variables and potential confounders (eg, major mood disorder) ${ }^{106}$ in samples of KLS patients. Reviews of the general KLS literature conclude that suicide attempts are rare among those with KLS. ${ }^{107,108}$ Even so, Arnulf et al suggested monitoring suicide risk in patients with KLS. ${ }^{108}$

\section{Insufficient-sleep syndrome}

A study of South Korean adolescents with behaviorally induced insufficient-sleep syndrome (BISS) showed that those with BISS had higher scores on measures of depression and suicide risk than adolescents without BISS and with sufficient sleep, adjusting for age and sex. ${ }^{55}$ Significant differences in regard to suicide risk remained when adjusting for depressive symptoms, and oversleeping on the weekend were associated with suicide risk independently of depression, insomnia symptoms, snoring, and daytime sleepiness, suggesting that chronic sleep deprivation may be an independent suicide risk factor. These results are consistent with other studies showing that Korean adolescents who slept longer on weekends were at greater risk of reporting a recent suicide attempt or self-injury ${ }^{109}$ and Chinese adolescents with greater suicide risk reporting short sleep duration during weekdays, increased sleep compensation and long sleep duration during weekends, and greater frequency of daytime napping. ${ }^{110}$ Furthermore, a more recent study of US adults showed that both long and short sleep durations were associated with suicide risk. ${ }^{111}$
Short sleep duration (defined in various studies as $\leq 4, \leq 5$, $\leq 6$, or $<8$ hours of sleep) has been associated with increased odds of suicide risk in samples of Taiwanese adults, ${ }^{57}$ US adolescents, ${ }^{102,112,113}$ and US Army soldiers following redeployment. ${ }^{114}$ Similar findings have been shown in samples of South Korean, ${ }^{115}$ Taiwanese, ${ }^{116}$ and Chinese adolescents ${ }^{117}$ (all were independent of depressive symptoms). Short sleep duration has also been associated with past 12-month suicide ideation and nonfatal suicide attempts in a South Korean adolescent sample (the relation was weaker for depressed adolescents vs nondepressed $)^{118}$ and in a community sample of US adults after adjusting for symptoms of depression, bipolar disorder, panic attacks, alcohol and substance dependence, and antisocial personality disorder. ${ }^{119}$ Increased risk of suicide ideation has also been shown among rural Chinese adolescents, ${ }^{120}$ European adolescents, ${ }^{121}$ US adolescents, ${ }^{122}$ and South Korean adolescents ${ }^{123}$ and adults ${ }^{124-126}$ reporting short sleep duration, and one study showed that male Spanish suicide-attempt survivors were more likely to report shorter sleep duration than psychiatric inpatient controls who denied a suicide-attempt history ${ }^{127}$ (short sleep duration was also associated with intent to attempt suicide among female attempt survivors, consistent with recent research). ${ }^{128}$

The potential importance of sleep duration in the development of suicide risk was emphasized in two longitudinal studies. The first showed that the wish to die among a small sample of French adults 1 month after an index suicidal crisis increased significantly with every lost hour of sleep, ${ }^{129}$ which is consistent with cross-sectional adolescent research showing that a 1-hour reduction in weekday sleep was related to an increased risk of hopelessness, suicide ideation, and suicide attempts (risk was higher for males). ${ }^{130}$ In a sample of adolescent monozygotic twins, the second study showed that a late bedtime and short sleep duration predicted future development of depressive and anxiety symptoms and suicide and self-injury risk (independently of bedtime regularity and genetic and shared environmental factors). ${ }^{131}$

Though it should be noted that inconsistencies exist, as one study showed that short sleep duration (ie, $\leq 5$ hours of sleep) and nonrestorative sleep were associated with last12-month suicide ideation, but not last-12-month suicide attempts in a sample of South Korean adolescents when adjusting for demographics, substance use, and depressive symptoms. ${ }^{132}$ More recent research showed depressive symptoms moderating the sleep duration-suicide risk relation among Chinese adolescents, ${ }^{133}$ and a study of South Korean adolescents showed that short weekday sleep duration was not associated with last-12-month suicide ideation or suicide 
attempts when included in regression models with demographic variables, weekend sleep duration, and depressive symptoms. ${ }^{109}$ Furthermore, a dated study showed that risk of death by suicide was not higher among those with short or long sleep duration. ${ }^{134}$

More research is needed on exploring for mechanisms or confounders of the suicide-risk relation that both insufficientsleep syndromes and sleep duration have demonstrated. Additionally, it is unknown if addressing sleep duration alone can alleviate risk of attempting suicide. Some researchers propose that for adolescents, parents may be able to increase sleep duration and decrease adolescent risk for depression and suicide ideation by setting earlier bedtimes ${ }^{122}$ and restricting electronic media access after bedtime. ${ }^{135}$

\section{Excessive daytime sleepiness}

Although excessive daytime sleepiness does not qualify as a sleep disorder, the prevalence of daytime sleepiness (a symptom present across several sleep disorders, eg, insomnia and narcolepsy) was shown to be higher among a sample of adolescent suicide decedents from the US when compared to community controls ( $13 \%$ vs $5 \%) .{ }^{23}$ Cross-sectional research has shown that excessive daytime sleepiness is associated with depression-symptom severity and suicide ideation and attempts in patients with depression, ${ }^{60}$ with those reporting more sleepiness showing higher self-reported levels of suicide ideation than those with less daytime sleepiness. ${ }^{136}$ However, a follow-up study showed that insomnia symptoms but not excessive daytime sleepiness were associated with suicide ideation when adjusting for demographic factors, depression duration, insomnia symptoms, and antidepressant/ hypnotic-medication use. ${ }^{44}$ In addition, results of the followup study showed that those with insomnia symptoms had significantly higher scores on the suicide-attempt planning and active and passive suicide-ideation components of the Beck Scale for Suicide Ideation ${ }^{137}$ than those with excessive daytime sleepiness. Also, no association was shown between excessive daytime sleepiness and suicide risk in a sample of adults admitted to an emergency department who presented with passive or active suicide ideation. ${ }^{129}$

\section{Circadian rhythm sleep-wake disorders}

Circadian rhythm sleep-wake disorders (CRSWDs) have not received much attention in terms of examining the prevalence of suicide-related thoughts and behaviors and identifying how specific sleep-wake disorders may impact one's risk for attempting suicide. The few studies that have been done have shown mixed results. Adults with bipolar disorder and a CRSWD had a greater likelihood of having a family history of suicide than participants without a CRSWD, ${ }^{138}$ though an earlier study of adults with bipolar disorder showed no differences between participants with delayed sleep phase, hypersomnia, insomnia, or no sleep problems with regard to the number of past suicide attempts. ${ }^{139}$ Furthermore, the prevalence of circadian reversal was not found to be significantly different in adolescent suicide decedents when compared to community controls. ${ }^{23}$ A more recent study of US adolescents showed that circadian reversal was associated with lifetime suicide attempts, but not suicide ideation or nonsuicidal self-injury, when adjusting for age, sex, depressive symptoms, insomnia symptoms, nonrestorative sleep, and hypersomnia. ${ }^{140}$

Research focusing on chronotypes have shown associations between an "eveningness" preference and suiciderelated thoughts ${ }^{141-144}$ and behaviors (ie, lifetime and violent suicide attempts). ${ }^{145,146}$ An eveningness preference has also been associated with elevated scores on measures of depressive symptoms, hopelessness, and defeat. ${ }^{147}$ Additionally, an eveningness preference coupled with short sleep duration was associated with greater odds of suicide ideation when adjusting for demographics, hopelessness, and past-month sleep problems due to bad dreams. ${ }^{141}$ Although associations have been shown between eveningness and suicide risk (current and lifetime), ${ }^{110,146}$ some studies have shown that eveningness was not associated with current (when adjusting for depressive symptoms) ${ }^{148}$ or lifetime suicide risk. ${ }^{147}$

Research focused on suicide-related variables has also been fairly absent among samples of participants experiencing jet lag or difficulties due to shift work. One of the few studies that examined shift work and suicide ideation showed an interaction of day shift and depressive symptoms for suicide ideation among female police officers, with female officers reporting higher levels of depression showing an increase in suicide ideation as day-shift hours increased. ${ }^{149}$ Among male police officers with higher levels of depression, suicide-ideation levels increased as the frequency of shift changes increased. It is generally unknown if treating CRSWDs can mitigate suicide risk, though one small study of depressed inpatients with suicide ideation showed a significant reduction in suicide risk following triple-chronotherapy treatment. ${ }^{150}$

\section{Parasomnias}

Most of the research published on parasomnias and suicide has focused on parasomnia conditions generally confined to 
REM sleep (ie, nightmares). Among the non-REM-related parasomnias, sleep paralysis was suggested as a precipitant to suicide-related behavior in one case study ${ }^{151}$ and suicide ideation was more likely to be endorsed among Taiwanese adolescents with concurrent sleep terrors and sleepwalking in a small case-control study. ${ }^{152}$ Sleepwalking has been suggested as a possible contributor to accidental nonfatal and fatal suicide attempts, ${ }^{153-156}$ but most of the research conducted in this area has been case studies. Similar concerns about accidental self-injurious behavior have been reported for patients with REM sleep-behavior disorder, ${ }^{157}$ with a retrospective chart review of sleep-clinic patients showing an increased prevalence of "acting out dreams" in adults with suicide ideation compared to those without ideation. ${ }^{158}$ Some researchers have suggested that the use of hypnotics (ie, zolpidem and eszopiclone) could heighten self-injury or suicide risk due to inducing parasomnia behavior that was absent prior to hypnotic use. ${ }^{159-162}$

\section{Nightmare disorder}

Research examining nightmares and suicide risk has focused more on the experience of nightmares versus the presence of a nightmare-disorder diagnosis, and few studies have examined the prevalence of suicide-related variables among those with nightmares (Table 4). The experience of bad dreams and nightmares has been associated with suicide ideation and suicide risk in samples of youth, ${ }^{117,120,163,164}$ adults, ${ }^{22,43,45,58,75,89,165-172}$ and older adults. ${ }^{52,173}$ Moreover, nightmares have been independently associated with lifetime,,$^{58,74,164,169}$ recent, ${ }^{58,76,171,174}$ and subsequent suicide attempts, ${ }^{58,75}$ including suicide. ${ }^{175,176}$ Importantly, the variance in suicide-related variables explained by nightmares across multiple studies has been independent of several potential confounders, including age, sex, anxiety and depressive symptoms, and the interpersonal-psychological theory of suicide. ${ }^{22,74,75,117,171,173}$

Nightmares have also independently predicted repeated suicide attempts in a sample of suicide-attempt survivors, ${ }^{75}$

Table 4 Prevalence of suicide-related thoughts and behaviors among participants with nightmares and proposed mechanisms of the nightmare-suicidality relation

\begin{tabular}{|c|c|}
\hline & revalence \\
\hline & $\begin{array}{l}\text { In a study of adults with a history of trauma, } 62 \% \text { who experienced nightmares during the past month reported suicide } \\
\text { ideation, suicide attempt planning, or a nonfatal suicide attempt, }{ }^{172} \text { and about } 96 \% \text { of adult participants in a separate study } \\
\text { who reported melancholic features and a suicide attempt during a current depressive episode reported experiencing } \\
\text { nightmares at least twice a week. }{ }^{76} \text { Among adolescents who often experience nightmares, } 40 \% \text { reported suicide } \\
\text { ideation (compared to } 13 \% \text { of those who denied nightmares); the percentage increased to } 50 \% \text { for those who reported } \\
\text { experiencing nightmares very often. }{ }^{28}\end{array}$ \\
\hline Proposed mediator & Summary of research \\
\hline Insomnia & $\begin{array}{l}\text { Some studies have suggested that insomnia symptoms may explain the relation between nightmares and suicide ideation } \\
\text { or a suicide-attempt history. An } 8 \text {-year observational study of adults with schizophrenia-spectrum disorders showed that } \\
\text { nightmares were associated with a history of suicide attempts, but only baseline insomnia symptoms were associated } \\
\text { with an increased risk of suicide attempt at follow-up, with coexisting insomnia symptoms and nightmares conferring an } \\
\text { elevenfold-increased risk for a future suicide attempt. }{ }^{59} \text { Additionally, among a primary-care clinic sample of older adults, } \\
\text { insomnia symptoms had an indirect effect on the association shown between nightmares and suicide ideation, }{ }^{52} \text { and } \\
\text { nightmares and insomnia symptoms predicted suicide ideation after I month (independently of baseline suicide ideation) in } \\
\text { an online sample of adults, but only insomnia symptoms independently predicted I month suicide ideation. }{ }^{203}\end{array}$ \\
\hline Negative affect & $\begin{array}{l}\text { Hochard et } \mathrm{al}^{204} \text { showed in a university sample that nightmares significantly increased the risk for future self-harm ideation } \\
\text { and behaviors and that negative affect had an indirect effect on this relation. However, the direct effect of nightmares } \\
\text { on self-harm risk was larger than the indirect effect, suggesting that negative affect cannot explain the majority of this } \\
\text { relation. }{ }^{182}\end{array}$ \\
\hline $\begin{array}{l}\text { Defeat, entrapment, } \\
\text { and hopelessness }\end{array}$ & $\begin{array}{l}\text { Littlewood et al }{ }^{172} \text { showed that the relation between nightmares and suicide risk is partially mediated by feelings of defeat, } \\
\text { entrapment, and hopelessness. Notably, the effects of this multiple-mediation model remained after adjusting for insomnia } \\
\text { symptoms and depression diagnosis. }\end{array}$ \\
\hline Nightmare distress & $\begin{array}{l}\text { A cross-sectional study of undergraduates showed that nightmare frequency had an indirect effect on suicide ideation } \\
\text { through nightmare distress, independently of insomnia symptoms. }{ }^{205} \text { In a moderated mediation analysis with sex as the } \\
\text { moderator, results showed that the indirect effect of nightmare distress on the nightmare frequency-suicide ideation } \\
\text { relation was significant only for women. }\end{array}$ \\
\hline IPTS & $\begin{array}{l}\text { Three studies have examined whether the IPTS could explain the nightmare-suicidality relation, with two studies showing } \\
\text { that the full IPTS could not fully account for this relation }{ }^{74,173} \text { and one showing that neither thwarted belongingness nor } \\
\text { perceived burdensomeness could fully account for the nightmare distress-suicide ideation relation. }{ }^{206} \text { However, it should } \\
\text { be noted that in the latter study, perceived burdensomeness partially mediated the nightmare distress-suicide ideation } \\
\text { relation, with a moderated mediation showing that this effect was significant only for women. }{ }^{206}\end{array}$ \\
\hline
\end{tabular}

Abbreviation: IPTS, interpersonal-psychological theory of suicide. 
and studies among adults and older adults have shown that the chronicity of nightmares may increase the risk of attempting suicide. ${ }^{173,177}$ However, in an online sample of US adults, nightmare frequency differentiated multiple and single suicide attempters independently of nightmare chronicity, nightmare severity/distress, and symptoms of depression, posttraumatic stress disorder, and insomnia in a sample of US adults (Speed et al, under review, 2017), suggesting that the number of nightmares experienced within a specific time frame may have greater relevance to predicting repeat suicide attempts than the length of time nightmares have been experienced.

Additional inconsistencies have been observed. For instance, nightmares were inversely associated with suicide ideation in a sample of Canadian military personnel and veterans ${ }^{178}$ and were not more frequent among depressed adolescent outpatients reporting suicide ideation or suicide intent. ${ }^{54}$ Also, two separate studies of adolescents failed to show an association between nightmares and suicide-related thoughts and behaviors, ${ }^{19,179}$ though one of the adolescent studies showed that parent-reported nightmares were not associated with suicide attempts ${ }^{179}$ and recent research showed discrepancies between parent and child reports on measures of distress, with more distressed children showing a greater likelihood of endorsing nightmares and suicide ideation than parents. ${ }^{180}$ Research has also shown an absence of suicide-related behavior among treatment-seeking patients with posttraumatic stress disorder and nightmares, ${ }^{181}$ and researchers suggest that stronger risk factors may exist that can explain the nightmare-suicide relation. ${ }^{176}$

As noted by Nadorff et al, ${ }^{182}$ progress is being made in the search for mechanisms that can explain the process whereby nightmares confer greater risk for suicide (see Table 4 for a review of mediator studies), but the management of suicide risk via nightmare treatment is one area that may deserve greater exploration. Results from an uncontrolled trial ${ }^{183}$ showed that imagery rehearsal therapy may resolve both nightmares and suicide ideation, with a case study suggesting that prazosin ${ }^{184}$ may also be effective in achieving similar outcomes. Both of these treatments have demonstrated efficacy in treating nightmares. ${ }^{185}$

\section{Sleep-related movement disorders}

Patients with restless-leg syndrome (RLS) appear at risk of developing depression, ${ }^{167}$ insomnia, anxiety, and pain disorders, ${ }^{186,187}$ conditions that have been associated with suicide risk..$^{23,188,189}$ Separate studies showed that $21 \%{ }^{190}$ and $38 \%{ }^{191}$ of sampled RLS patients endorsed thoughts of suicide. Depressed RLS patients are also more likely than controls to blame RLS symptoms entirely for their depressive symptoms, sleep problems, and suicide-related thoughts. ${ }^{191}$ Additional research is needed among RLS patients, as it is unknown if concurrent psychiatric illness or insomnia symptoms can explain the increased prevalence of suicide ideation noted. There also is a paucity of research focused on investigating suicide risk among other sleep-related movement disorders. This includes periodic limb-movement disorder, sleep-related leg cramps, sleep-related bruxism, sleep-related rhythmic movement disorder, propriospinal myoclonus at sleep onset, and sleep-related movement disorder due to a medical disorder or medication/substance use.

\section{Conclusion}

This narrative review has revealed multiple research avenues with regard to sleep disorders and suicide risk. Although the impact of some sleep-disorder symptoms on suicide risk has been investigated extensively (ie, insomnia), we still know very little about the prevalence of suicide risk across sleep disorders and the impact these disorders have on suicidality independently of known risk factors (eg, depression). We also know little about whether managing sleep problems via evidence-based treatments can mitigate risk for suicide, and if effective, what populations seem to benefit most from such management. At this point, we can make the argument that sleep disturbances may be a marker of distress and suicide risk $^{127}$ and that multiple concurrent sleep problems may confer greater risk for suicide than single sleep problems. ${ }^{66,141}$ Mechanisms explaining the relation between sleep disorders and suicide remain needed, including more research rigorously examining the efficacy of sleep-disorder treatments on assuaging suicide risk. Research examining the impact of sleep disorders on suicide risk has been circumscribed to a few sleep-disorder symptoms, with much less known about the prevalence and management of suicide risk across all sleep disorders. Therefore, opportunities abound for current and prospective sleep and suicide researchers.

\section{Disclosure}

The authors report no conflicts of interest in this work.

\section{References}

1. World Health Organization. Global Health Observatory data repository. 2016. Available from: http://www.who.int/gho/data/node.home. Accessed August 30, 2017.

2. World Health Organization. Preventing Suicide: A Global Imperative Geneva: WHO; 2014.

3. Centers for Disease Control and Prevention. Web-based injury statistics query and reporting system (WISQARS). 2017. Available from: https:// www.cdc.gov/injury/wisqars/index.html. Accessed August 30, 2017. 
4. Ford ES, Wheaton AG, Cunningham TJ, Giles WH, Chapman DP, Croft JB. Trends in outpatient visits for insomnia, sleep apnea, and prescriptions for sleep medications among US adults: findings from the National Ambulatory Medical Care survey 1999-2010. Sleep. 2014;37:1283-1293.

5. Stranges S, Tigbe W, Gómez-Olivé FX, Thorogood M, Kandala NB. Sleep problems: an emerging global epidemic? Findings from the INDEPTH WHO-SAGE study among more than 40,000 older adults from 8 countries across Africa and Asia. Sleep. 2012;35:1173-1181.

6. Bernert RA, Nadorff MR. Sleep disturbances and suicide risk. Sleep Med Clin. 2015;10:35-39.

7. Bernert RA, Kim JS, Iwata NG, Perlis ML. Sleep disturbances as an evidence-based suicide risk factor. Curr Psychiatry Rep. 2015;17:554.

8. Pigeon WR, Bishop TM, Titus CE. The relationship between sleep disturbance, suicidal ideation, suicide attempts, and suicide among adults: a systematic review. Psychiatr Ann. 2016;46:177-186.

9. Pigeon WR, Pinquart M, Conner K. Meta-analysis of sleep disturbance and suicidal thoughts and behaviors. J Clin Psychiatry. 2012;73:e1160-e1167.

10. Bernert RA, Joiner TE. Sleep disturbances and suicide risk: a review of the literature. Neuropsychiatr Dis Treat. 2007;3:735-743.

11. American Academy of Sleep Medicine. International Classification of Sleep Disorders. 3rd ed. Darien (IL): AASM; 2014

12. Morin CM, LeBlanc M, Daley M, Gregoire JP, Mérette C. Epidemiology of insomnia: prevalence, self-help treatments, consultations, and determinants of help-seeking behaviors. Sleep Med. 2006;7:123-130.

13. Ohayon M. Epidemiology of insomnia: what we know and what we still need to learn. Sleep Med Rev. 2002;6:97-111.

14. Ohayon M. Prevalence of DSM-IV diagnostic criteria of insomnia: distinguishing insomnia related to mental disorders from sleep disorders. J Psychiatr Res. 1997;31:333-346.

15. Pallesen S, Nordhus IH, Nielsen GH, et al. Prevalence of insomnia in the adult Norwegian population. Sleep. 2001;24:771-779.

16. Pallesen S, Sivertsen B, Nordhus IH, Bjorvatn B. A 10-year trend of insomnia prevalence in the adult Norwegian population. Sleep Med. 2014; 15:173-179.

17. Bailly D, Bailly-Lambin I, Querleu D, Beuscart R, Collinet C. Le sommeil des adolescents et ses troubles une enquête en milieu scolaire. [Sleep in adolescents and its disorders: a survey in schools]. Encephale. 2004;30:352-359. French.

18. Trockel M, Karlin BE, Taylor CB, Brown GK, Manber R. Effects of cognitive behavioral therapy for insomnia on suicidal ideation in veterans. Sleep. 2015;38:259-265.

19. Wong MM, Brower KJ, Zucker RA. Sleep problems, suicidal ideation, and self-harm behaviors in adolescence. J Psychiatr Res. 2011;45:505-511.

20. Tishler CL, McKenry PC, Morgan KC. Adolescent suicide attempts: some significant factors. Suicide Life Threat Behav. 1981;11:86-92.

21. Hall RC, Platt DE, Hall RC. Suicide risk assessment: a review of risk factors for suicide in 100 patients who made severe suicide attempts evaluation of suicide risk in a time of managed care. Psychosomatics. 1999;40:18-27.

22. Sjöströma N, Waern M, Hettab J. Nightmares and sleep disturbances in relation to suicidality in suicide attempters. Sleep. 2007;30:91-95.

23. Goldstein TR, Bridge JA, Brent DA. Sleep disturbance preceding completed suicide in adolescents. J Consult Clin Psychol. 2008;76:84-91.

24. Sun L, Zhang J, Liu X. Insomnia symptom, mental disorder and suicide: a case-control study in Chinese rural youths. Sleep Biol Rhythms. 2015;13:181-188.

25. Kodaka M, Matsumoto T, Katsumata Y, et al. Suicide risk among individuals with sleep disturbances in Japan: a case-control psychological autopsy study. Sleep Med. 2014;15:430-435.

26. Hung GC, Kwok CL, Yip PS, Gunnell D, Chen YY. Predicting suicide in older adults: a community-based cohort study in Taipei City, Taiwan. J Affect Disord. 2015;172:165-170.

27. Choquet M, Kovess V, Poutignat N. Suicidal thoughts among adolescents: an intercultural approach. Adolescence. 1993;28:649-659.
28. Choquet M, Menke H. Suicidal thoughts during early adolescence: prevalence, associated troubles and help-seeking behavior. Acta Psychiatr Scand. 1990;81:170-177.

29. Kitagawa Y, Ando S, Yamasaki S, et al. Appetite loss as a potential predictor of suicidal ideation and self-harm in adolescents: a schoolbased study. Appetite. 2017;111:7-11.

30. Wong MM, Brower KJ. The prospective relationship between sleep problems and suicidal behavior in the National Longitudinal Study of Adolescent Health. J Psychiatr Res. 2012;46:953-959.

31. Wong MM, Brower KJ, Craun EA. Insomnia symptoms and suicidality in the National Comorbidity Survey: adolescent supplement. J Psychiatr Res. 2016;81:1-8.

32. Barbe RP, Williamson DE, Bridge JA, et al. Clinical differences between suicidal and nonsuicidal depressed children and adolescents. J Clin Psychiatry. 2005;66:492-498.

33. McCall WV, Blocker JN, D'Agostino R Jr, et al. Insomnia severity is an indicator of suicidal ideation during a depression clinical trial. Sleep Med. 2010;11:822-827.

34. Pigeon WR, Woosley JA, Lichstein KL. Insomnia and hypnotic medications are associated with suicidal ideation in a community population. Arch Suicide Res. 2014;18:170-180.

35. Fisher K, Houtsma C, Assavedo BL, Green BA, Anestis MD. Agitation as a moderator of the relationship between insomnia and current suicidal ideation in the military. Arch Suicide Res. Epub 2016 Jul 19.

36. Bryan CJ, Gonzales J, Rudd MD, et al. Depression mediates the relation of insomnia severity with suicide risk in three clinical samples of U.S. military personnel. Depress Anxiety. 2015;32:647-655.

37. Bozzay ML, Karver MS, Verona E. Linking insomnia and suicide ideation in college females: the role of socio-cognitive variables and depressive symptoms in suicide risk. J Affect Disord. 2016;199:106-113.

38. Nadorff MR, Nazem S, Fiske A. Insomnia symptoms, nightmares, and suicidal ideation in a college student sample. Sleep. 2011;34:93-98.

39. Chu C, Hom MA, Rogers ML, et al. Is insomnia lonely? Exploring thwarted belongingness as an explanatory link between insomnia and suicidal ideation in a sample of South Korean university students. J Clin Sleep Med. 2016;12:647-652.

40. Chakravorty S, Grandner MA, Mavandadi S, Perlis ML, Sturgis EB, Oslin DW. Suicidal ideation in veterans misusing alcohol: relationships with insomnia symptoms and sleep duration. Addict Behav. 2014;39:399-405.

41. Kato T. Insomnia symptoms, depressive symptoms, and suicide ideation in Japanese white-collar employees. Int J Behav Med. 2014;21:506-510.

42. Tang WK, Lu JY, Liang $\mathrm{H}$, et al. Is insomnia associated with suicidality in stroke? Arch Phys Med Rehabil. 2011;92:2025-2027.

43. McCall WV, Batson N, Webster M, et al. Nightmares and dysfunctional beliefs about sleep mediate the effect of insomnia symptoms on suicidal ideation. J Clin Sleep Med. 2013;9:135-140.

44. Chellappa SL, Araújo JF. Sleep disorders and suicidal ideation in patients with depressive disorder. Psychiatry Res. 2007;153:131-136.

45. Pederson CL, Brook JB. Sleep disturbance linked to suicidal ideation in postural orthostatic tachycardia syndrome. Nat Sci Sleep. 2017;9:109-115.

46. Chakravorty S, Siu HY, Lalley-Chareczko L, et al. Sleep duration and insomnia symptoms as risk factors for suicidal ideation in a nationally representative sample. Prim Care Companion CNS Disord. Epub 2015 Dec 31.

47. Hom MA, Chu C, Schneider ME, et al. Thwarted belongingness as an explanatory link between insomnia symptoms and suicidal ideation: findings from three samples of military service members and veterans. J Affect Disord. 2017;209:114-123.

48. Ribeiro JD, Pease JL, Gutierrez PM, et al. Sleep problems outperform depression and hopelessness as cross-sectional and longitudinal predictors of suicidal ideation and behavior in young adults in the military. J Affect Disord. 2012;136:743-750. 
49. Lee JI, Lee MB, Liao SC, et al. Prevalence of suicidal ideation and associated risk factors in the general population. J Formos Med Assoc. 2010;109:138-147.

50. Bernert RA, Luckenbaugh DA, Duncan WC, Iwata NG, Ballard ED, Zarate CA. Sleep architecture parameters as a putative biomarker of suicidal ideation in treatment-resistant depression. J Affect Disord. 2017;208:309-315

51. Smith MT, Perils ML, Haythornthwaite JA. Suicidal ideation in outpatients with chronic musculoskeletal pain: an exploratory study of the role of sleep onset insomnia and pain intensity. Clin J Pain. 2004;20:111-118.

52. Nadorff MR, Fiske A, Sperry JA, Petts R, Gregg JJ. Insomnia symptoms, nightmares, and suicidal ideation in older adults. J Gerontol B Psychol Sci Soc Sci. 2013;68:145-152.

53. Chiu HF, Dai J, Xiang YT, et al. Suicidal thoughts and behaviors in older adults in rural China: a preliminary study. Int $J$ Geriatr Psychiatry. 2012;27:1124-1130.

54. Urrila AS, Karlsson L, Kiviruusu O, Pelkonen M, Strandholm T, Marttunen M. Sleep complaints among adolescent outpatients with major depressive disorder. Sleep Med. 2012;13:816-823.

55. Lee YJ, Cho SJ, Cho IH, Kim SJ. Insufficient sleep and suicidality in adolescents. Sleep. 2012;35:455-460.

56. Chu C, Hom MA, Rogers ML, et al. Insomnia and suicide-related behaviors: a multi-study investigation of thwarted belongingness as a distinct explanatory factor. J Affect Disord. 2017;208:153-162.

57. Gunnell D, Chang SS, Tsai MK, Tsao CK, Wen CP. Sleep and suicide: an analysis of a cohort of 394,000 Taiwanese adults. Soc Psychiatry Psychiatr Epidemiol. 2013;48:1457-1465.

58. Li SX, Lam SP, Yu MW, Zhang J, Wing YK. Nocturnal sleep disturbances as a predictor of suicide attempts among psychiatric outpatients: a clinical, epidemiologic, prospective study. J Clin Psychiatry. 2010;71:1440-1446.

59. Li SX, Lam SP, Zhang J, et al. Sleep disturbances and suicide risk in an 8-year longitudinal study of schizophrenia-spectrum disorders. Sleep. 2016;39:1275-1282.

60. Lopes MC, Boronat AC, Wang YP, Fu-I L. Sleep complaints as risk factor for suicidal behavior in severely depressed children and adolescents. CNS Neurosci Ther. 2016;22:915-920.

61. Kay DB, Dombrovski AY, Buysse DJ, Reynolds CF, Begley A, Szanto $\mathrm{K}$. Insomnia is associated with suicide attempt in middle-aged and older adults with depression. Int Psychogeriatr. 2016;28:613-619.

62. McGirr A, Renaud J, Seguin M, et al. An examination of DSMIV depressive symptoms and risk for suicide completion in major depressive disorder: a psychological autopsy study. J Affect Disord. 2007;97:203-209.

63. Fawcett J, Scheftner WA, Fogg L, et al. Time-related predictors of suicide in major affective disorder. Am J Psychiatry. 1990;147:1189-1194

64. Pigeon WR, Britton PC, Ilgen MA, Chapman B, Conner KR. Sleep disturbance preceding suicide among veterans. Am J Public Health. 2012;102:S93-S97.

65. Fujino Y, Mizoue T, Tokui N, Yoshimura T. Prospective cohort study of stress, life satisfaction, self-rated health, insomnia, and suicide death in Japan. Suicide Life Threat Behav. 2005;35:227-237.

66. Rod NH, Vahtera J, Westerlund H, et al. Sleep disturbances and cause-specific mortality: results from the GAZEL cohort study. Am J Epidemiol. 2011;173:300-309.

67. Barraclough BM, Pallis DJ. Depression followed by suicide: a comparison of depressed suicides with living depressives. Psychol Med. 2009;5:55-61.

68. Bernert RA, Turvey CL, Conwell Y, Joiner T. Sleep disturbance as a unique risk factor for completed suicide. Journal of Sleep and Sleep Disorder Research. 2007;30:A0977.

69. Bernert RA, Turvey CL, Conwell Y, Joiner TE. Association of poor subjective sleep quality with risk for death by suicide during a 10-year period: a longitudinal, population-based study of late life. JAMA Psychiatry. 2014;71:1129-1137.

70. Pompili M, Innamorati M, Forte A, et al. Insomnia as a predictor of high-lethality suicide attempts. Int J Clin Pract. 2013;67:1311-1316.
71. Allan NP, Conner KR, Pigeon WR, Gros DF, Salami TK, Stecker T. Insomnia and suicidal ideation and behaviors in former and current U.S. service members: does depression mediate the relations? Psychiatry Res. 2017;252:296-302.

72. Carli V, Roy A, Bevilacqua L, Maggi S, Cesaro C, Sarchiapone M. Insomnia and suicidal behaviour in prisoners. Psychiatry Res. 2011;185:141-144.

73. Wojnar M, Ilgen MA, Wojnar J, McCammon RJ, Valenstein M, Brower KJ. Sleep problems and suicidality in the National Comorbidity Survey replication. J Psychiatr Res. 2009;43:526-531.

74. Nadorff MR, Anestis MD, Nazem S, Harris HC, Winer ES. Sleep disorders and the interpersonal-psychological theory of suicide: independent pathways to suicidality? J Affect Disord. 2014;152-154:505-512.

75. Sjöströma N, Hettab J, Waern M. Persistent nightmares are associated with repeat suicide attempt: a prospective study. Psychiatry Res. 2009;170:208-211.

76. Agargun MY, Besiroglu L, Cilli AS, et al. Nightmares, suicide attempts, and melancholic features in patients with unipolar major depression. $J$ Affect Disord. 2007;98:267-270.

77. Littlewood D, Kyle SD, Pratt D, Peters S, Gooding P. Examining the role of psychological factors in the relationship between sleep problems and suicide. Clin Psychol Rev. 2017;54:1-16.

78. Winer ES, Cervone D, Bryant J, McKinney C, Liu RT, Nadorff MR. Distinguishing mediational models and analyses in clinical psychology: atemporal associations do not imply causation. J Clin Psychol. 2016;72:947-955.

79. Pigeon WR, Caine ED. Insomnia and the risk for suicide: does sleep medicine have interventions that can make a difference? Sleep Med. 2010;11:816-817.

80. Agargun MY, Beşiroğlu L. Sleep and suicidality: do sleep disturbances predict suicide risk? Sleep. 2005;28:1039-1040.

81. Liu X, Buysse DJ. Sleep and youth suicidal behavior: a neglected field Curr Opin Psychiatry. 2006;19:288-293.

82. McCall WV. Insomnia is a risk factor for suicide: what are the next steps? Sleep. 2011;34:1149-1150.

83. Winsper C, Tang NK. Linkages between insomnia and suicidality: prospective associations, high-risk subgroups and possible psychological mechanisms. Int Rev Psychiatry. 2014;26:189-204.

84. Pigeon WR, Funderburk J, Bishop TM, Crean HF. Brief cognitive behavioral therapy for insomnia delivered to depressed veterans receiving primary care services: a pilot study. $J$ Affect Disord. 2017;217:105-111.

85. Qaseem A, Kansagara D, Forciea M, Cooke M, Denberg TD. Management of chronic insomnia disorder in adults: a clinical practice guideline from the American College of Physicians. Ann Intern Med. 2016;165:125-133.

86. Manber R, Bernert RA, Suh S, Nowakowski S, Siebern AT, Ong JC. CBT for insomnia in patients with high and low depressive symptom severity: adherence and clinical outcomes. J Clin Sleep Med. 2011;7:645-652.

87. Mallon L, Broman JE, Hetta J. Is usage of hypnotics associated with mortality? Sleep Med. 2009;10:279-286.

88. Brower KJ, McCammon RJ, Wojnar M, Ilgen MA, Wojnar J, Valenstein M. Prescription sleeping pills, insomnia, and suicidality in the National Comorbidity Survey replication. J Clin Psychiatry. 2011;72:515-521.

89. Bernert RA, Joiner TE Jr, Cukrowicz KC, Schmidt NB, Krakow B Suicidality and sleep disturbances. Sleep. 2005;28:1135-1141.

90. Bishop TM, Ashrafioun L, Pigeon WR. Association between sleep apnea and suicidal thought and behavior. Sleep. 2017;40:A414-A415.

91. Krakow B, Artar A, Warner TD, et al. Sleep disorder, depression, and suicidality in female sexual assault survivors. Crisis. 2000;21:163-170.

92. Hagen C, Patel A, McCall WV. Prevalence of insomnia symptoms in sleep laboratory patients with and without sleep apnea. Psychiatry Res. 2009; 170:276-277.

93. Krakow B, Melendrez D, Ferreira E, et al. Prevalence of insomnia symptoms in patients with sleep-disordered breathing. Chest. 2001;120:1923-1929. 
94. Smith S, Sullivan K, Hopkins W, Douglas J. Frequency of insomnia report in patients with obstructive sleep apnoea hypopnea syndrome (OSAHS). Sleep Med. 2004;5:449-456.

95. Krahn LE, Miller BW, Bergstrom LR. Rapid resolution of intense suicidal ideation after treatment of severe obstructive sleep apnea. J Clin Sleep Med. 2008;4:64-65.

96. Schwartz DJ, Kohler WC, Karatinos G. Symptoms of depression in individuals with obstructive sleep apnea may be amenable to treatment with continuous positive airway pressure. Chest. 2005;128:1304-1309.

97. Edwards C, Mukherjee S, Simpson L, Palmer LJ, Almeida OP, Hillman DR. Depressive symptoms before and after treatment of obstructive sleep apnea in men and women. J Clin Sleep Med. 2015;11:1029-1038.

98. Ohayon MM, Black J, Lai C, Eller M, Guinta D, Bhattacharyya A. Increased mortality in narcolepsy. Sleep. 2014;37:439-444.

99. Ruoff CM, Reaven NL, Funk SE, et al. High rates of psychiatric comorbidity in narcolepsy: findings from the Burden of Narcolepsy Disease (BOND) study of 9,312 patients in the United States. $J$ Clin Psychiatry. 2017;78:171-176.

100. Ohayon MM. A longitudinal study of 322 individuals with narcolepsy. Ann Neurol. 2012;72:S21.

101. Roberts RE, Roberts CR, Chen IG. Functioning of adolescents with symptoms of disturbed sleep. J Youth Adolesc. 2001;30:1-18.

102. Fitzgerald CT, Messias E, Buysse DJ. Teen sleep and suicidality: results from the Youth Risk Behavior surveys of 2007 and 2009. J Clin Sleep Med. 2011;7:351-356.

103. Ağargün MY, Kara H, Solmaz M. Sleep disturbances and suicidal behavior in patients with major depression. J Clin Psychiatry. 1997;58: 249-251.

104. Soehner AM, Kaplan KA, Harvey AG. Prevalence and clinical correlates of co-occurring insomnia and hypersomnia symptoms in depression. J Affect Disord. 2014;167:93-97.

105. Arnulf I, Lin L, Gadoth N, et al. Kleine-Levin syndrome: a systematic study of 108 patients. Ann Neurol. 2008;63:482-493.

106. Geoffroy PA, Arnulf I, Etain B, Henry C. Kleine-Levin syndrome and bipolar disorder: a differential diagnosis of recurrent and resistant depression. Bipolar Disord. 2013;15:899-902.

107. Miglis MG, Guilleminault C. Kleine-Levin syndrome. Curr Neurol Neurosci Rep. 2016;16:60.

108. Arnulf I, Rico TJ, Mignot E. Diagnosis, disease course, and management of patients with Kleine-Levin syndrome. Lancet Neurol. 2012;11:918-928.

109. Kang SG, Lee YJ, Kim SJ, et al. Weekend catch-up sleep is independently associated with suicide attempts and self-injury in Korean adolescents. Compr Psychiatry. 2014;55:319-325.

110. Gau SS, Shang CY, Merikangas KR, Chiu YN, Soong WT, Cheng AT. Association between morningness-eveningness and behavioral/emotional problems among adolescents. J Biol Rhythms. 2007;22:268-274.

111. Michaels MS, Balthrop T, Nadorff MR, Joiner TE. Total sleep time as a predictor of suicidal behaviour. J Sleep Res. Epub 2017 Jun 1.

112. Daly BP, Jameson JP, Patterson F, McCurdy M, Kirk A, Michael KD. Sleep duration, mental health, and substance use among rural adolescents: developmental correlates. $J$ Rural Ment Health. 2015;39:108-122.

113. McKnight-Eily LR, Eaton DK, Lowry R, Croft JB, Presley-Cantrell L, Perry GS. Relationships between hours of sleep and health-risk behaviors in US adolescent students. Prev Med. 2011;53:271-273.

114. Luxton DD, Greenburg D, Ryan J, Niven A, Wheeler G, Mysliwiec V. Prevalence and impact of short sleep duration in redeployed OIF soldiers. Sleep. 2011;34:1189-1195.

115. Park TJ, Kim J. Is insufficient sleep duration associated with suicidal behavior in Korean adolescents? Sleep Biol Rhythms. 2017;15: 117-125.

116. Yen CF, King BH, Tang TC. The association between short and long nocturnal sleep durations and risky behaviours and the moderating factors in Taiwanese adolescents. Psychiatry Res. 2010;179:69-74.

117. Liu X. Sleep and adolescent suicidal behavior. Sleep. 2004; 27:1351-1358.
118. Jang SI, Lee KS, Park EC. Relationship between current sleep duration and past suicidal ideation or attempt among Korean adolescents. J Prev Med Public Health. 2013;46:329-335.

119. Goodwin RD, Marusic A. Association between short sleep and suicidal ideation and suicide attempt among adults in the general population. Sleep. 2008;31:1097-1101.

120. Jia CX, Li SB, Han M, Bo QG. Health-related factors and suicidal ideation in high school students in rural China. Omega. 2016;73:263-274.

121. Sarchiapone M, Mandelli L, Carli V, Niven A, Wheeler G, Mysliwiec V. Hours of sleep in adolescents and its association with anxiety, emotional concerns, and suicidal ideation. Sleep Med. 2014;15: 248-254.

122. Gangwisch JE, Babiss LA, Malaspina D, Turner JB, Zammit GK, Posner K. Earlier parental set bedtimes as a protective factor against depression and suicidal ideation. Sleep. 2010;33:97-106.

123. Kim YJ, Kim KH, Kwon HJ, Kim JS. Associations between adolescents' sleep duration, sleep satisfaction, and suicidal ideation. Salud Ment (Mex). 2016;39:213-219.

124. Chin YR, Lee HY, So ES. Suicidal ideation and associated factors by sex in Korean adults: a population-based cross-sectional survey. Int $J$ Public Health. 2011;56:429-439.

125. An KO, Jang JY, Kim J. Sedentary behavior and sleep duration are associated with both stress symptoms and suicidal thoughts in Korean adults. Tohoku J Exp Med. 2015;237:279-286.

126. Lee MS, Shin JS, Lee J, et al. The association between mental health, chronic disease and sleep duration in Koreans: a cross-sectional study. BMC Public Health. 2015;15:1200.

127. Blasco-Fontecilla H, Alegria AA, Lopez-Castroman J, et al. Short self-reported sleep duration and suicidal behavior: a cross-sectional study. J Affect Disord. 2011;133:239-246.

128. Ferentinos P, Porichi E, Christodoulou C, Dikeos D, Papageorgiou C, Douzenis A. Sleep disturbance as a proximal predictor of suicidal intent in recently hospitalized attempters. Sleep Med. 2016;19:1-7.

129. Mirsu-Paun A, Jaussent I, Komar G, Courtet P, Lopez-Castroman J. Sleep complaints associated with wish to die after a suicide crisis: an exploratory study. J Sleep Res. Epub 2017 Apr 24.

130. Winsler A, Deutsch A, Vorona RD, Payne PA, Szklo-Coxe M. Sleepless in Fairfax: the difference one more hour of sleep can make for teen hopelessness, suicidal ideation, and substance use. $J$ Youth Adolesc. 2015;44:362-378.

131. Matamura M, Tochigi M, Usami S, et al. Associations between sleep habits and mental health status and suicidality in a longitudinal survey of monozygotic twin adolescents. J Sleep Res. 2014;23:292-296.

132. Park JH, Yoo JH, Kim SH. Associations between non-restorative sleep, short sleep duration and suicidality: findings from a representative sample of Korean adolescents. Psychiatry Clin Neurosci. 2013;67:28-34.

133. Guo L, Xu Y, Deng J, et al. Association between sleep duration, suicidal ideation, and suicidal attempts among Chinese adolescents: the moderating role of depressive symptoms. J Affect Disord. 208: 355-362.

134. Kripke DF, Garfinkel L, Wingard DL, Klauber MR, Marler MR. Mortality associated with sleep duration and insomnia. Arch Gen Psychiatry. 2002;59:131-136.

135. Seo JH, Kim JH, Yang KI, Hong SB. Late use of electronic media and its association with sleep, depression, and suicidality among Korean adolescents. Sleep Med. 2017;29:76-80.

136. Chellappa SL, Araujo JF. Excessive daytime sleepiness in patients with depressive disorder. Rev Bras Psiquiatr. 2006;28:126-129.

137. Beck AT, Kovacs M, Weissman A. Assessment of suicidal intention: the scale for suicide ideation. J Consult Clin Psychol. 1979;47:343-352.

138. Takaesu Y, Inoue Y, Murakoshi A, et al. Prevalence of circadian rhythm sleep-wake disorders and associated factors in euthymic patients with bipolar disorder. PLoS One. 2016;11:e0159578.

139. Steinan MK, Morken G, Lagerberg TV, et al. Delayed sleep phase: an important circadian subtype of sleep disturbance in bipolar disorders. J Affect Disord. 2016;191:156-163. 
140. McGlinchey EL, Courtney-Seidler EA, German M, Miller AL. The role of sleep disturbance in suicidal and nonsuicidal self-injurious behavior among adolescents. Suicide Life Threat Behav. 2016;47:103-111.

141. Matsumoto Y, Uchimura N, Ishida T, et al. Day workers suffering from a wider range of sleep problems are more likely to experience suicidality. Sleep Biol Rhythms. 2016;14:369-376.

142. Park YM, Lee SH. Chronotype in relation to bipolarity, suicidal ideation, and auditory evoked potentials in patients with major depressive disorder: preliminary study. Korean J Biol Psychiatry. 2014;21:14-20.

143. Bahk YC, Han E, Lee SH. Biological rhythm differences and suicidal ideation in patients with major depressive disorder. $J$ Affect Disord. 2014;168:294-297.

144. Gaspar-Barba E, Calati R, Cruz-Fuentes CS, et al. Depressive symptomatology is influenced by chronotypes. J Affect Disord. 2009;119:100-106.

145. Selvi Y, Aydin A, Atli A, Boysan M, Selvi F, Besiroglu L. Chronotype differences in suicidal behavior and impulsivity among suicide attempters. Chronobiol Int. 2011;28:170-175.

146. Chan JW, Lam SP, Li SX, et al. Eveningness and insomnia: independent risk factors of nonremission in major depressive disorder. Sleep. 2014;37:911-917.

147. Lester D. Morningness-eveningness, current depression, and past suicidality. Psychol Rep. 2015;116:331-336.

148. Selvi Y, Aydin A, Boysan M, Atli A, Agargun MY, Besiroglu L. Associations between chronotype, sleep quality, suicidality, and depressive symptoms in patients with major depression and healthy controls. Chronobiol Int. 2010;27:1813-1828.

149. Violanti JM, Charles LE, Hartley TA, et al. Shift-work and suicide ideation among police officers. Am J Ind Med. 2008;51:758-768.

150. Sahlem GL, Kalivas B, Fox JB, et al. Adjunctive triple chronotherapy (combined total sleep deprivation, sleep phase advance, and bright light therapy) rapidly improves mood and suicidality in suicidal depressed inpatients: an open label pilot study. J Psychiatr Res. 2014;59: 101-107.

151. Hosty G, Abbott J. Sleep paralysis and attempted suicide: a case report. Ir J Psychol Med. 2014;17:71-72.

152. Gau SF, Soong WT. Psychiatric comorbidity of adolescents with sleep terrors or sleepwalking: a case-control study. Aust N Z J Psychiatry. 1999;33:734-739.

153. Lauerma H. Fear of suicide during sleepwalking. Psychiatry. 1996;59:206-211.

154. Seeman MV. Sleepwalking, a possible side effect of antipsychotic medication. Psychiatr Q. 2011;82:59-67.

155. Shatkin JP, Feinfield K, Strober M. The misinterpretation of a nonREM sleep parasomnia as suicidal behavior in an adolescent. Sleep Breath. 2002;6:175-179.

156. Mahowald MW, Schenck CH, Goldner M, Bachelder V, CramerBornemann M. Parasomnia pseudo-suicide. J Forensic Sci. 2003;48:1158-1162.

157. Schenck CH, Lee SA, Bornemann MA, Mahowald MW. Potentially lethal behaviors associated with rapid eye movement sleep behavior disorder: review of the literature and forensic implications. J Forensic Sci. 2009;54:1475-1484.

158. Krakow B, Ribeiro JD, Ulibarri VA, Krakow J, Joiner TE Jr. Sleep disturbances and suicidal ideation in sleep medical center patients. $J$ Affect Disord. 2011;131:422-427.

159. Ben-Hamou M, Marshall NS, Grunstein RR, Saini B, Fois RA. Spontaneous adverse event reports associated with zolpidem in Australia 2001-2008. J Sleep Res. 2011;20:559-568.

160. McCall WV, Benca RM, Rosenquist PB, et al. Hypnotic medications and suicide: risk, mechanisms, mitigation, and the FDA. Am J Psychiatry. 2017;174:18-25.

161. Gibson CE, Caplan JP. Zolpidem-associated parasomnia with serious self-injury: a shot in the dark. Psychosomatics. 2011;52:88-91.

162. Pennington JG, Guina J. Eszopiclone-induced parasomnia with suicide attempt: a case report. Innov Clin Neurosci. 2016;13:44-48.
163. Kaplan SG, Ali SK, Simpson B, Britt V, McCall WV. Associations between sleep disturbance and suicidal ideation in adolescents admitted to an inpatient psychiatric unit. Int J Adolesc Med Health. 2014;26:411-416.

164. Mayes SD, Fernandez-Mendoza J, Baweja R, et al. Correlates of suicide ideation and attempts in children and adolescents with eating disorders. Eat Disord. 2014;22:352-366.

165. Cukrowicz KC, Otamendi A, Pinto JV, Bernert RA, Krakow B, Joiner TE Jr. The impact of insomnia and sleep disturbances on depression and suicidality. Dreaming. 2006;16:1-10.

166. Chellappa SL, Araújo JF. [Clinical significance of nightmares in patients with depressive disorder]. Rev Psiquiatr Clin. 2006;33: 183-187. Portuguese.

167. Li SX, Lam SP, Chan JW, Yu MW, Wing YK. Residual sleep disturbances in patients remitted from major depressive disorder: a 4-year naturalistic follow-up study. Sleep. 2012;35:1153-1161.

168. Ağargün MY, Cilli AS, Kara H, Tarhan N, Kincir F, Oz H. Repetitive and frightening dreams and suicidal behavior in patients with major depression. Compr Psychiatry. 1998;39:198-202.

169. Lai YC, Huang MC, Chen HC, et al. Familiality and clinical outcomes of sleep disturbances in major depressive and bipolar disorders. J Psychosom Res. 2014;76:61-67.

170. Marinova P, Koycheva I, Laleva L, et al. Nightmares and suicide: predicting risk in depression. Psychiatr Danub. 2014;26:159-164

171. Susánszky E, Hajnal A, Kopp M. [Sleep disturbances and nightmares as risk factors for suicidal behavior among men and women]. Psychiatr Hung. 2011;26:250-257. Hungarian.

172. Littlewood DL, Gooding PA, Panagioti M, Kyle SD. Nightmares and suicide in posttraumatic stress disorder: the mediating role of defeat, entrapment, and hopelessness. J Clin Sleep Med. 2016;12:393-399.

173. Golding S, Nadorff MR, Winer ES, Ward KC. Unpacking sleep and suicide in older adults in a combined online sample. J Clin Sleep Med. 2015;11:1385-1392.

174. Agargun MY, Kara H, Ozer, OA, Selvi Y, Kiran U, Ozer B. Clinical importance of nightmare disorder in patients with dissociative disorders. Psychiatr Clin Neurosci. 2003;57:575-579.

175. Tanskanen A, Tuomilehto J, Viinamäki H, Vartiainen E, Lehtonen J, Puska P. Nightmares as predictors of suicide. Sleep. 2001;24:844-847.

176. Sandman N, Valli K, Kronholm E, Vartiainen E, Laatikainen T, Paunio T. Nightmares as predictors of suicide: an extension study including war veterans. Sci Rep. 2017;7:44756.

177. Nadorff MR, Nazem S, Fiske A. Insomnia symptoms, nightmares, and suicide risk: duration of sleep disturbance matters. Suicide Life Threat Behav. 2013;43:139-149.

178. Richardson JD, Cyr KS, Nelson C, Elhai JD, Sareen J. Sleep disturbances and suicidal ideation in a sample of treatment-seeking Canadian Forces members and veterans. Psychiatry Res. 2014;218:118-123.

179. Koyawala N, Stevens J, McBee-Strayer SM, Cannon EA, Bridge JA. Sleep problems and suicide attempts among adolescents: a case-control study. Behav Sleep Med. 2015;13:285-295.

180. Bein LA, Petrik ML, Saunders SM, Wojcik JV. Discrepancy between parents and children in reporting of distress and impairment: association with critical symptoms. Clin Child Psychol Psychiatry. 2015;20:515-524.

181. Gupta M, Vujcic B. Posttraumatic stress disorder (PTSD) with nightmares is associated with a significantly lower frequency of suicidal behavior: results from a nationally representative US sample. Biol Psychiatry. 2017;81:S89-S90.

182. Nadorff MR, Pearson MD, Golding S. Explaining the relation between nightmares and suicide. J Clin Sleep Med. 2016;12:289-290.

183. Ellis, TE, Rufino, KA, Nadorff MR. Treatment of nightmares in psychiatric inpatients with imagery rehearsal therapy: an open trial and case series. Behav Sleep Med. Epub 2017 Mar 23

184. Johnson KG, Rosen J. Re-emergence of posttraumatic stress disorder nightmares with nursing home admission: treatment with prazosin. J Am Med Dir Assoc. 2013;14:130-131. 
185. Nadorff MR, Lambdin KK, Germain A. Pharmacological and nonpharmacological treatments for nightmare disorder. Int Rev Psychiatry. 2014;26:225-236.

186. Becker PM, Novak M. Diagnosis, comorbidities, and management of restless legs syndrome. Curr Med Res Opin. 2014;30:1441-1460.

187. Becker PM, Sharon D. Mood disorders in restless legs syndrome (Willis-Ekbom disease). J Clin Psychiatry. 2014;75:e679-e694.

188. Chesney E, Goodwin GM, Fazel S. Risks of all-cause and suicide mortality in mental disorders: a meta-review. World Psychiatry. 2014;13:153-160.

189. Nepon J, Belik SL, Bolton J, Sareen J. The relationship between anxiety disorders and suicide attempts: findings from the national epidemiologic survey on alcohol and related conditions. Depress Anxiety. 2010;27:791-798.

190. Talih F, Ajaltouni J, Kobeissy F. Restless leg syndrome in hospitalized psychiatric patients in Lebanon: a pilot study. Neuropsychiatr Dis Treat. 2016;12:2581-2586.

191. Winkelmann J, Prager M, Lieb R, et al. “Anxietas tibiarum”: depression and anxiety disorders in patients with restless legs syndrome. $J$ Neurol. 2005;252:67-71.

192. Britton PC, Ilgen MA, Valenstein M, Knox K, Claassen CA, Conner KR. Differences between veteran suicides with and without psychiatric symptoms. Am J Public Health. 2012;102:S125-S130.

193. Nrugham L, Larsson B, Sund AM. Specific depressive symptoms and disorders as associates and predictors of suicidal acts across adolescence. J Affect Disord. 2008;111:83-93.

194. Woosley JA, Lichstein KL, Taylor DJ, Riedel BW, Bush AJ. Hopelessness mediates the relation between insomnia and suicidal ideation. J Clin Sleep Med. 2014;10:1223-1230.

195. Curtis A, Agarwal G, Attarian H. Treatment of subjective total insomnia after suicide attempt with olanzapine and electroconvulsive therapy. J Clin Psychopharmacol. 2016;36:178-180.
196. McCall WV, Black CG. The link between suicide and insomnia: theoretical mechanisms. Curr Psychiatry Rep. 2013;15:389.

197. Woosley JA, Lichstein KL, Taylor DJ, Riedel BW, Bush AJ. Insomnia complaint versus sleep diary parameters: predictions of suicidal ideation. Suicide Life Threat Behav. 2016;46:88-95.

198. Nadorff MR, Ellis TE, Allen JG, Winer ES, Herrera S. Presence and persistence of sleep-related symptoms and suicidal ideation in psychiatric inpatients. Crisis. 2014;35:398-405.

199. Sandman N, Valli K, Kronholm E, Ollila H, Laatikainen T, Paunio T. Prevalence of nightmares among the general Finnish adult population and veterans of the Second World War. Sleep Med. 2013;14:e34.

200. Dolsen MR, Cheng P, Arnedt JT, et al. Neurophysiological correlates of suicidal ideation in major depressive disorder: hyperarousal during sleep. J Affect Disord. 2017;212:160-166.

201. Rogers ML, Schneider ME, Tucker RP, Law KC, Anestis MD, Joiner TE. Overarousal as a mechanism of the relation between rumination and suicidality. J Psychiatr Res. 2017;92:31-37.

202. Joiner TE. Why People Die by Suicide. Cambridge (MA): Harvard University Press; 2005.

203. Nadorff MR, Drapeau CW, Winer ES, Kilgore JK. Nightmares and insomnia symptoms prospectively predict the development of suicidal ideation. Sleep. 2017;40:A416.

204. Hochard KD, Heym N, Townsend E. The unidirectional relationship of nightmares on self-harmful thoughts and behaviors. Dreaming. 2015;25:44-58.

205. Lee R, Suh S. Nightmare distress as a mediator between nightmare frequency and suicidal ideation. Dreaming. 2016;26: 308-318.

206. Suh S, Schneider M, Lee R, Joiner T. Perceived interpersonal burdensomeness as a mediator between nightmare distress and suicidal ideation in nightmare sufferers. Front Psychol. 2016;7:1805.
Nature and Science of Sleep

\section{Publish your work in this journal}

Nature and Science of Sleep is an international, peer-reviewed, open access journal covering all aspects of sleep science and sleep medicine, including the neurophysiology and functions of sleep, the genetics of sleep, sleep and society, biological rhythms, dreaming, sleep disorders and therapy, and strategies to optimize healthy sleep. The manuscript

\section{Dovepress}

management system is completely online and includes a very quick and fair peer-review system, which is all easy to use. Visit http://www. dovepress.com/testimonials.php to read real quotes from published authors. 